\title{
Origin and Distribution of Water Amongst the Inner Planets
}

\author{
Andrew J. R. Prentice \\ School of Mathematical Sciences, Monash University, Victoria 3800, \\ Australia
}

\begin{abstract}
A new model for the origin and bulk chemical composition of the inner planets, especially for their water content, is reported.
\end{abstract}

There is a growing body of evidence that the planets of the inner Solar system condensed within narrow, compositionally-distinct annuli, close to their present orbital radii (Drake \& Righter 2002). Such a picture is consistent with the Laplacian nebular hypothesis, namely that the planetary system had formed from a concentric family of gas rings. Such rings were shed by the contracting proto-solar cloud [hereafter PSC] as a means for disposing of excess spin angular momentum (Prentice 1978). A new model for the PSC has been constructed. It consists of an adiabatic convective core surrounded by a super-adiabatic envelope of negative polytropic index. This structure is suggested by numerical simulations of supersonic thermal convection in a model atmospheric layer (Prentice \& Dyt 2003). The cloud possesses a radial turbulent stress whose ratio to the gas pressure achieves a maximum value $\sim 15$ at the core/envelope boundary. If the controlling parameters stay constant, the PSC contracts homologously and sheds gas rings whose mean orbital radii $R_{n}(n=0,1,2, \cdots)$ are nearly geometrically spaced. The ring mean temperatures $T_{n}$ vary with $R_{n}$ as $T_{n} \simeq A / R_{n}^{0.9}$, where $A$ is a constant (Prentice 2001a). Choosing iron-rich Mercury to calibrate $A$ (Prentice 2001b), Venus forms at $917 \mathrm{~K}$ and is totally anhydrous. The initial Earth $(678 \mathrm{~K})$ has 0.0023 , by mass fraction, of water tied up in tremolite. Mars $(460 \mathrm{~K})$ contains an $\mathrm{H}_{2} \mathrm{O}$ mass fraction of 0.00295 in tremolite and 0.0027 in $(\mathrm{Na}, \mathrm{K}) \mathrm{OH}$. The asteroids $(275 \mathrm{~K})$ contain 0.0027 of $\mathrm{H}_{2} \mathrm{O}$ in $(\mathrm{Na}, \mathrm{K}) \mathrm{OH}$. Mars is thus the most water-rich of all the inner planets. Other predicted bulk constituents of Mars are: $\mathrm{MgAl}_{2} \mathrm{O}_{4}(0.0324), \mathrm{MgSiO}_{3}-\mathrm{Mg}_{2} \mathrm{SiO}_{4}$ (0.3677), $\mathrm{Fe}_{2} \mathrm{SiO}_{4}(0.1796)$, Fe$\mathrm{Ni}-\mathrm{Cr}(0.0533),(\mathrm{Fe}-\mathrm{Ni}) \mathrm{S}(0.2042), \mathrm{MnS} \& \mathrm{ZnS}(0.0050), \mathrm{NaCl}(0.0016), \mathrm{Cr}_{2} \mathrm{O}_{3}$ $\& \mathrm{FeTiO}_{3}(0.0065)$ and $\mathrm{P}_{2} \mathrm{O}_{5}(0.0031)$.

\section{References}

Drake, M. J., \& Righter, K. 2002, Nature, 416, 39

Prentice, A. J. R. 1978, Moon \& Planets, 19, 341

Prentice, A. J. R. 2001a, Earth Moon \& Planets, 87, 11

Prentice, A. J. R. 2001b in LPI Contribution No. 1097, Workshop on Mercury: Space Environment, Surface, and Interior, ed. M. S. Robinson \& G. J. Taylor (Houston: Lunar \& Planetary Institute), 81

Prentice, A. J. R., \& Dyt, C. P. 2003, MNRAS, 341, 644 